\title{
Integrate Collaborative and Innovation Concepts into Big Data Major's Construction
}

\author{
Shaolin Li \\ Tourism Data College \\ Guilin Tourism University \\ Guilin, China \\ Lslg11966@163.com
}

\begin{abstract}
In order to cultivate big data talents with theoretical and practical ability, the methods of establishing big data major in tourism colleges were discussed in this paper. Guilin Tourism University's mathematics and computer theory's teachers are teacher-resources for professional basic courses; the Guangxi Tourism Data Center is used as a place of experimental training for students; high-tech companies are cooperated with and their scientific and technical personnel are as professional curriculum instructors to meet big data professional needs. Under the guidance of the instructors, the concepts of collaborative and innovation are used to integrate into the construction of the big data profession in the Tourism colleges. This method of professional construction has been widely recognized by students and their parents, and the enrollment situation is excellent. Follow above, tourism colleges with weak engineering can cultivate big data talents with tourism characteristics.
\end{abstract}

Keywords-Integration; Big Data Talents; Specialty Construction; Collaborative; Innovation

\section{INTRODUCTION}

In the era of big data, a large number of composite big data professionals are needed. At present, big data talents are seriously insufficient for demand. At the same time, the training of big data talents requires universities to have a typical interdisciplinary high-level training ability. At present, in addition to some famous engineering universities, many colleges lack relevant laboratories, training bases and professional teachers.

After a large number of social surveys on the demand for big data talents, Guilin Tourism University established a big data major in 2019. The major had high-reward students in the enrollment work in September 2019. How can non-technical tourism universities train qualified students with social needs? It is extremely important to study the construction of big data major with tourism characteristics. The methods of building disciplines for big data major will be discussed in this paper. It will be discussed how to use the Guangxi Tourism Data Center as a platform for teaching experiments, how to use the computer foundation and mathematics teachers as the teachers of theoretical teaching, how to use the big data professional science and technology personnel of social high-tech companies as professional teacher resources, how to use the concept of collaborative innovation in professional construction. After consulting a large number of literatures on talent development, it will be discussed that the discipline construction plan based on professional needs. For example, basic theory teaching programs, professional and practical training programs, etc. It is very important to carry out discipline construction on the concept of collaborative innovation. Students will have the knowledge of a strong ability to carry out high-tech work. The content of the above discussion has a great significance for the companies. It can shorten the time of employee training and make new employees quickly become the technical backbone of tourism big data processing.

\section{BASIC CONCEPTS}

\section{A. Collaborative Innovation Concept}

Collaborative innovation is the sharing mechanism of knowledge, thought, professional skills and technology. It is characterized by common goals, internal motivation and communication. It will rely on modern information technology to build a platform for the resource. This resource platform may realize multi-dimensional and diversified collaboration ${ }^{[1]}$.

Collaborative innovation is a complex way of innovation organization. The key is to form a multi-agent collaborative and innovation mode of interactive network, which takes university, enterprise, research institutions as a core element, they will do in-depth cooperation and resource integration.

The main characteristics of collaborative innovation with non-linear utility are as follows:

(A) Integrity: Innovation ecosystem is an organic collection of various elements rather than simple addition. It shows unified integrity on an existing way, objective, as well as function

(B) Dynamics: The innovation ecosystem is constantly moving. It is a new paradigm of scientific and technological innovation to integrate complementary resources. It realizes the complementary advantages of all parties to accelerate the application of technology. It carries out technological innovation, as well as the conversion of scientific and technological achievements in collaboration.

\section{B. Big Data and Big Date Talents}

As a kind of massive data, large data is generated and aggregated continuously from different sources, which has a certain scale and come from a variety of data sources. It has a 
the main contents in big data specialty's study. It will be not discussed in detail.

Secondly, the mathematical theory of big data is very important. In the large data of internet, many analysis objects of application scenarios can be abstracted into matrix representation. A large number of web pages and their relationships, micro-blog users and their relationships, and the relationship between text and vocabulary in text set can be represented by matrix. For example, when a web page and its relationship are represented by a matrix, the matrix element represents the relationship between pages $\mathrm{A}$ and another page B. This relationship can be a pointing relationship. 1 indicates that there is a hyperlink between A and B, 0 indicates that there is no hyperlink between $\mathrm{A}$ and $\mathrm{B}$. The famous PageRank algorithm is based on this matrix to quantify the importance of pages and prove its convergence. Matrix-based operations, such as matrix decomposition, which are the way to extract the features of analytical objects, because the matrix represents some transformation or mapping, the decomposed matrix represents some new features of analytical objects in the new space. Therefore, SVD, PCA, NMF and MF are widely used in large data analysis.

Finally, there is a lot of knowledge that will be studied, for example, engineering application, data analysis and mining, etc. All of the above knowledge will be used largely in the process of big data learning. In the course design, the unit design will be combined with the training project.

\section{E. Courses offered}

According to the knowledge needs of talents with big data, the curriculum is divided into professional basic courses and professional courses. Each university can choose the following courses according to the university's characteristics and application needs.

For example, Higher Mathematics, Big Data Science and Technology, Introduction to Tourism, Programming Language Foundation, Linear Algebra, Discrete Mathematics, Image Processing, Database Foundation and Application, Linux System and Application, Probability Theory , Mathematical Statistics, Computer Network, Object-Oriented Programming, Big Data Technology Architecture, Data Warehouse Technology, Data Structure, Statistical- Analysis and Application of Large Data, Advanced Database System, Large Data Application Development Language, Tourism Data Mining and Analysis, Machine Learning, Algorithm Analysis and Design, and so on.

\section{F. Laboratory and Experimental Base}

The Tourism Data College of Guilin Tourism University has an experimental center and a scientific research base with Guangxi Tourism Data Center as the core. Guangxi Tourism Data Center is a provincial tourism data center set up within Guilin Tourism College as approved by the autonomous region. It is fully responsible for tourism statistics, economic accounting, monitoring and early warning, publication, international exchanges and cooperation, theoretical construction of tourism statistics in the whole region of Guangxi, and tourism statistics of local governments. Its data analysis is data development of relevant enterprise institutions computer theory, computer programming language, web page design language, the principles of various algorithms, the use of data mining tools, database knowledge and so on, they are
Firstly, because of the computer as the main processing tool of large data processing, it is well known that large data talents 
training program will be adjusted to achieve a virtuous circle of talent training models. equipment is more than 10 million yuan. At present, it has realtime access to multi-dimensional data sources such as communication operators, tourism consumption data and Internet data. It has established data information databases and data sharing and exchange platforms including 13 categories and 90 sub-categories such as ASEAN tourism database and has formulated standardized standards for data collection, storage and exchange.

The major of big data set up by the college has an experimental and training platform. Under the guidance of teachers, students can complete the task of analysis and processing about big tourism data, and dig out useful tourism service information. This can not only improve students' professional skills, but also contribute useful data to Guangxi Tourism Data Center. All of these will achieve collaborative innovation in teaching and scientific research.

\section{PROFESSIONAL ORIENTATION OF SPECIALTY CONSTRUCTION}

\section{A. Discipline Construction Oriented by Career Needs}

The big data talent training model based on social needs can better avoid the lack of relevant laboratories, training bases and teachers in colleges and universities.

In the process of building a big data profession, it is necessary to adhere to new technologies and adhere to innovative ideas. It is important to strive to explore and innovate in talent training, discipline construction, organizational management and educational integration. It is also important to work hard to develop high-quality, multidisciplinary talents with ethics and intelligence. These talents should have big data thinking, a new generation of information technology, solid basic knowledge of tourism, innovation and entrepreneurial capabilities.

Guided by social needs, we adopt a "school-enterprise joint construction" talent training model and explore a new model of school-enterprise cooperation. By sharing high-quality educational resources, a new talent development mechanism between universities and industry leaders will be created. Facing the whole country, it will provide advanced information technology such as big data; cloud computing, artificial intelligence, Internet of Things, and virtual reality technology to provide big data talents for the tourism industry.

Grasping the source of social needs, the direction of talent cultivation is no longer blind. Courses, credit arrangements, practical teaching, and the construction of the teaching staff are also very clear. The students' ability to apply the industry has been improved. Enterprises can not only help students solve practical problems, but also solve employment problems and achieve a win-win situation. Universities can directly acquire the demand characteristics of big data talents of social enterprises through enterprise alliances and school-enterprise alliances. They can also get demand through indirect channels and then tailor the training of big data talents as needed. Apply joint training of big data talents to these social institutions and evaluate the effectiveness of joint training based on application effectiveness. According to the assessment results, the joint

\section{B. Professional Construction Model of Collaborative Innovation}

The goal of collaborative innovation is to build a collaborative innovation training model based on the Collaborative Innovation Center, which guides the reform and innovation of the training model. The Center promotes teaching reform, research reform and innovation with the concept of collaborative innovation. The comprehensive reform of the talent training model includes teaching content.

A training system will be established that includes teaching methods, practical exercises, innovation platforms and management mechanisms. It will conducive to diversified and innovative talents, thus forming a number of innovative talent training bases. It will meet the local needs of a lack of innovative and applied talent.

Establish a coordination and cooperation mechanism for student training, combining discipline development, research and personnel training. Together with high-tech companies and data centers, the College has established a number of coconstruction alliances to explore ways to actively share quality education resources. Coordination and cooperation mechanisms will provide a joint training for students and collaborative innovation in training the top data and talent in the tourism industry. Explore and establish cooperation between data centers and enterprises, and work together in the center to build a high-quality resource platform. Conduct multi-faceted exchanges, carry out diversified cooperation, and improve the quality of student training. Explore the mechanisms and models for the integration of scientific research, disciplines, and laboratories, and establish a laboratory model through cooperative enterprises to link the advanced technology and equipment of enterprises with practical teaching. Form a group of student practice platforms with industry characteristics.

Rely on the advantages of universities, base on the foundation of the original enterprise practice on the basis of long-term cooperation with the company, build a mutually beneficial and win-win talent training cooperation platform. Engage the company's experienced external internship teachers to build a combination of schools and businesses.

Make full use of the foundation of the college and integrate with research institutions to conduct basic theoretical research, core technology development and laboratory simulation. Establish a number of relatively independent cooperative innovation platforms, integrate personnel training, and solve major problems.

\section{Big Data Promotes Tourism Development}

Big data is mainly used for tourism market segmentation, tourism marketing diagnosis, dynamic monitoring of scenic spots, and monitoring of tourism public opinion. Through the amount of tourism data, it can effectively enhance the ability of collaborative management and public services, and promote the analysis of tourists' portraits and public opinion through a large 
major and build a big data major with tourism characteristics, we must make full use of internal and external advantages, and carry out professional construction with the concept of collaborative innovation.

Firstly, this paper introduced the concept of collaborative innovation, big data talent and big data professional.

Secondly, professional courses and experimental bases were introduced. Taking the construction of big data major of Guilin Tourism University as an example, it introduced the university courses provided according to professional needs. Guangxi Tourism Data Center is used as the experimental practice base of students, and discussed the integration of the resources of mathematics and computer theory teachers in Guilin Tourism College. Based on the concept of collaborative innovation, it was discussed the plans for big data professional construction, including the technical resources of professional teachers and professional technicians in high-tech enterprises, and the experimental teaching resources of Guangxi Tourism Data Center.

Thirdly, this paper introduced the professional positioning of professional construction. It included the following contents: (A) Discipline construction oriented to occupational needs (B) Professional construction model of collaborative innovation (C) Big data promotes the development of tourism. In order to cultivate the big data talents that meet the needs of enterprises and solve the shortage of big data talents in the tourism industry, some suggestions have been put forward to further improve the training mode of big data talents in tourism universities.

\section{REFERENCES}

[1] Sun Yan, Chen Yan, Han Bing, and Xie Zhiwen. "Training mode of master's degree in surface engineering from the perspective of collaborative innovation". China Metallurgical Education, April 2019, pp.89-91. (In Chinese).

[2] Wang Zuo. "Rebuilding Enterprise Competitiveness in the Big Data Era". China's Circulation Economy, vol. 31, pp. 3-13., December. 2017. (In Chinese).

[3] Sun Shengli. "Enterprise Information Management Strategy in Big Data Era". Electronic Technology and Software Engineering, June 2018 pp.168. (In Chinese).

[4] Wang Yaya. "Research on enterprise customer relationship management based on data mining technology". Shenzhen University. 2017. (In Chinese).

[5] Chen Yongping, Li He. "Logistics Terminal Distribution, Consumer Experience Demand Satisfaction and Value Creation Ability Improvement in the Big Data Era ". Financial Theories Series, January 2017, pp. 95-104. (In Chinese).

[6] Wu Linke. "Study on Government Support Strategies in the Development of Intelligent Tourism in Xuzhou". China University of Mining and Technology, 2019. (In Chinese).
Big data talents are high-tech talents that combine multiple elements of knowledge. As a tourism university, how to use the characteristics of tourism universities to establish a big data 